\title{
How to use clinical signs of meningitis
}

\author{
Alexander Tracy (D) ,' Thomas Waterfield ${ }^{2}$
}

- Additional material is published online only. To view please visit the journal online (http://dx.doi.org/10.1136/ archdischild-2018-315428).

${ }^{1}$ General Paediatrics, Birmingham Children's Hospital, Birmingham, UK

${ }^{2}$ School of Medicine, Dentistry and Biomedical Sciences, Queen's University Belfast, Belfast, UK

\section{Correspondence to}

Dr Alexander Tracy, General Paediatrics, Birmingham

Children's Hospital, Birmingham

B46NH, UK; alexander.tracy@ nhs.net

Accepted 11 November 2018 Published Online First 28 January 2019

\begin{abstract}
Meningitis is a critical diagnosis not to miss in children presenting with fever. Since the early 20th century, classical clinical signs have been used to aid the diagnosis of meningitis. These classical signs are nuchal rigidity, Kernig's sign and Brudzinski's sign. Each of these relies on the principle that stretching the inflamed meningeal membranes causes clinically detectable irritation. Several primary studies have quantified the diagnostic performance of clinical examination in detecting meningitis in children. The results of these studies vary significantly due to methodological differences, clinical heterogeneity and interobserver variability. However, their findings demonstrate that positive meningitic signs increase the likelihood of a diagnosis of meningitis, and the absence of meningitic signs reduces this probability. These signs have greatest utility when combined with other features in the history and examination to contribute to a comprehensive clinical assessment.
\end{abstract}

\section{BACKGROUND}

Meningitis describes inflammation of the meninges, which can be subclassified by aetiology (box 1). The most critical diagnosis to identify is bacterial meningitis as this has a poor prognosis when unrecognised.

\section{Box 1 Key definitions}

- Meningitis - a disease characterised by inflammation of the meninges. Meningitis may be due to bacterial, tuberculous, viral or fungal infections, or may be aseptic. Causes of aseptic meningitis include partially treated infections, neoplastic disease, drug administration and systemic inflammatory diseases.

- Meningism - a clinical syndrome of signs and symptoms that are suggestive of meningeal irritation. Symptoms may include headache, photophobia, neck stiffness and seizures. Signs may include nuchal rigidity, Kernig's sign, Brudzinski's sign or jolt accentuation headache.

Definitive diagnosis of meningitis is made on examination of cerebrospinal fluid obtained at lumbar puncture (LP). Clinical assessment plays an important role in stratification of patients before LP according to pretest probability of meningitis. Traditionally, the identification of clinical signs on examination is used to assess likelihood of meningitis. Nuchal rigidity, Kernig's sign and Brudzinski's sign are classical signs that date from the early 20th century but are still used routinely in paediatric practice. ${ }^{1}$
A

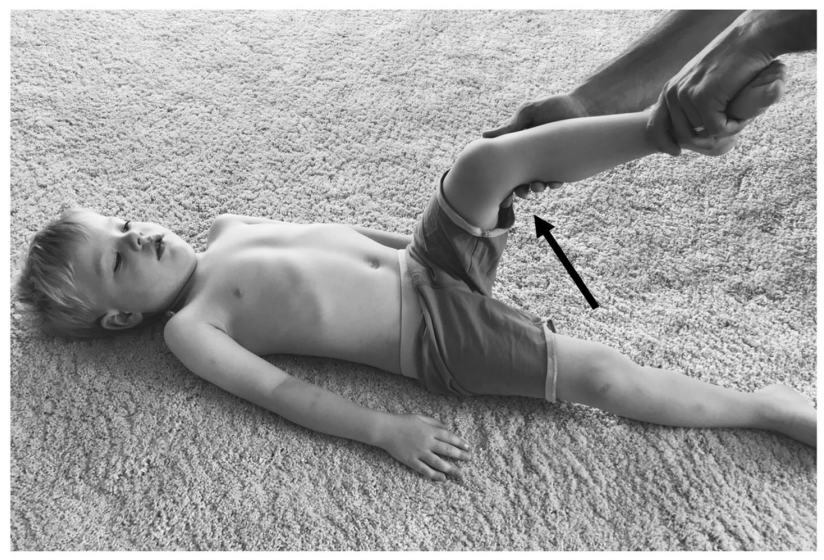

Kernig's Sign
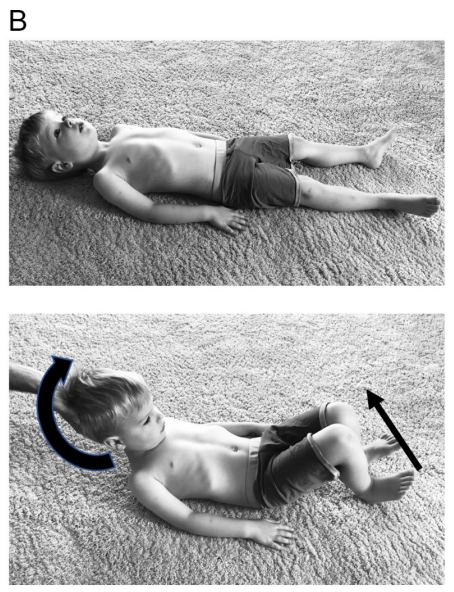

Brudzinski's Sign

To cite: Tracy A, Waterfield T. 2020;105:46-49.

Figure 1 How to examine for clinical signs of meningism. (A) Kernig's sign. (B) Brudzinski's sign. 


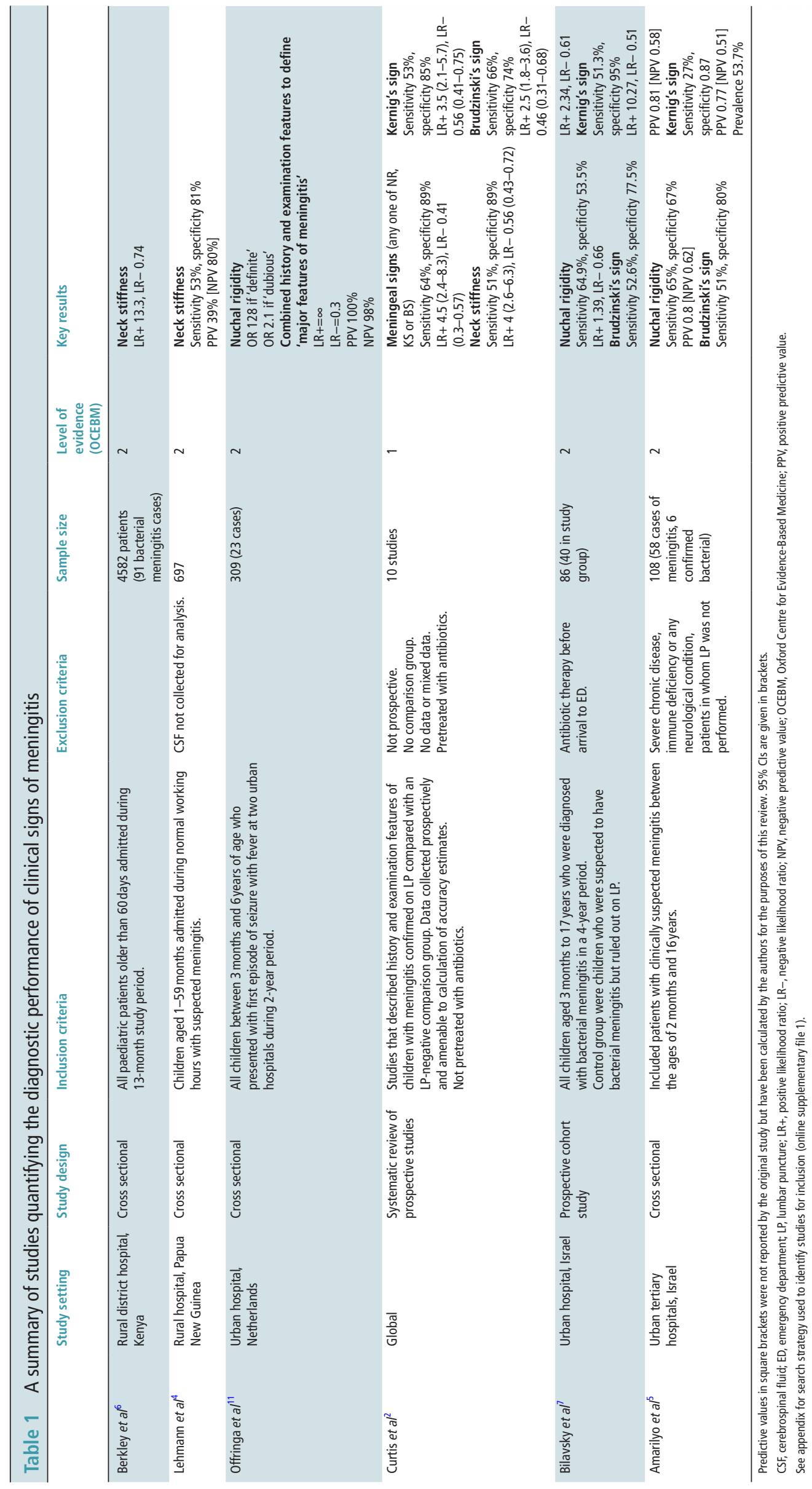


Table 2 Negative predictive values and likelihood ratios for clinical signs of meningitis

\begin{tabular}{lll}
\hline Clinical sign & $\begin{array}{l}\text { Negative predictive } \\
\text { values* }\end{array}$ & $\begin{array}{l}\text { Likelihood ratios of } \\
\text { negative result }\end{array}$ \\
\hline Nuchal rigidity & 0.62 to 0.80 & 0.56 to 0.74 \\
Kernig's sign & 0.51 & 0.51 to 0.56 \\
Brudzinski's sign & 0.58 & 0.46 to 0.61 \\
\hline
\end{tabular}

A quantitative summary of how effectively the absence of each clinical sign alone rules out a diagnosis of meningitis.

*Predictive values and likelihood ratios derived from studies summarised in table $1 .{ }^{24-7}$

The physiological principle underlying these tests is that meningeal irritation can be elicited by performing certain movements. In each test, the clinician aims to stretch the meninges and thus elicit features of meningeal irritation (box 2).

To test for nuchal rigidity, the examiner flexes the patient's neck and the test is positive if there is palpable resistance to passive flexion. To test for Kernig's sign, the patients are positioned supine with their hips flexed to $90^{\circ}$. Kernig's sign is present if there is pain on passive knee extension. To elicit Brudzinski's sign, the patients lie supine and their necks are passively flexed by the examining clinician. The test is positive if this causes reflex flexion of the hip and knee. Figure 1 and online supplementary figure 2 demonstrates how to test for Kernig's sign and Brudzinski's sign.

\section{SCENARIOS}

Case 1: In febrile children over the age of 1 year, can the absence of clinical signs of meningism rule out meningitis?

Studies reporting the diagnostic accuracy of clinical signs of meningitis are summarised in table 1 . Of note, these studies were performed in different populations, using inconsistent reference standards across a range of healthcare contexts including high and low-resource settings (box 3).

Even with these variations in study design and setting, all studies demonstrated that the absence of clinical signs of meningism reduced the likelihood of meningitis, with a combined negative likelihood ratio of 0.41 (95\% CI 0.3 to 0.57$){ }^{2}$ Table 2 further summarises the performance of different signs in isolation.

As with all diagnostic tests, it is necessary to consider the pretest probability when applying the test to clinical practice. A recent prospective study of 5517 paediatric hospital attendances with acute illness (excluding trauma, intoxication and exacerbation of chronic conditions) found that only $0.308 \%$ of children were diagnosed with meningitis. ${ }^{3}$ Using this as a pretest probability, the risk of meningitis in a child presenting with an acute illness without signs of meningism is $0.1 \%$ (table 4 ).

In summary, absence of clinical signs of meningitis suggests a very low risk of meningitis assuming a low pretest probability. The absence of clinical signs

\section{Box 2 How to test for clinical signs of meningitis}

- Neck stiffness: Passively flex the patient's neck. This test is positive if there is palpable resistance.

- Kernig's sign: Position the patients supine with their hips flexed to $90^{\circ}$. This test is positive if there is pain on passive extension of the knee.

- Brudzinski's sign: Position the patients supine and passively flex their neck. This test is positive if this manoeuvre causes reflex flexion of the hip and knee.

Box 3 Limitations of research on diagnostic value of clinical signs of meningitis

- Inconsistent diagnostic reference standard.

- Uncertain microbiology, which is sometimes confounded by pretreatment with antibiotics.

- Low patient numbers, often making it impossible to test the performance of each sign for identification of bacterial meningitis per se.

- Interobserver variability.

- Variability between study settings, for example, developed versus developing world.

is reassuring in low-risk children, but meningitis can occur without clinical signs of meningism.

Case 2: In febrile children over the age of 1 year, does the presence of clinical signs of meningism confirm the diagnosis of meningitis?

As summarised in table 3 , the positive predictive values for each clinical sign vary between 0.39 and $0.81 .{ }^{45}$ The likelihood ratios for positive results range from 1.39 to 13.3. ${ }^{267}$ These data demonstrate that the presence of clinical signs of meningism increases the likelihood of meningitis.

However, as shown in table 4, the risk of meningitis remains under $1 \%$ even in the presence of signs of meningitis. This is due to the low prevalence of meningitis in febrile children. Although the overall risk remains low in children aged over 1 year, the presence of clinical signs of meningism confers an increased risk of meningitis. In this situation, further investigation including LP is likely to be required.

Table 3 Positive predictive values and likelihood ratios for clinical signs of meningitis

\begin{tabular}{lll}
\hline Clinical sign & $\begin{array}{l}\text { Positive predictive } \\
\text { values* }\end{array}$ & $\begin{array}{l}\text { Likelihood ratios of } \\
\text { positive result }\end{array}$ \\
\hline Nuchal rigidity & 0.39 to 0.8 & 1.39 to 13.3 \\
Kernig's sign & 0.77 & 3.5 to 10.27 \\
Brudzinski's sign & 0.81 & 2.34 to 2.5 \\
\hline
\end{tabular}

A quantitative summary of the likelihood of a diagnosis of meningitis given positive clinical signs.

* Predictive values and likelihood ratios derived from studies summarised in table $1 .{ }^{24-7}$ 


\begin{tabular}{|c|c|c|c|}
\hline $\begin{array}{l}\text { Pre-test } \\
\text { probability of } \\
\text { meningitis in } \\
\text { children with } \\
\text { acute illness (\%) }\end{array}$ & \multicolumn{2}{|c|}{$\begin{array}{l}\text { Clinical examination } \\
\text { finding }\end{array}$} & \multirow{2}{*}{$\begin{array}{l}\text { Post-test } \\
\text { probability of } \\
\text { meningitis (\%) }\end{array}$} \\
\hline \multirow{6}{*}{0.308} & \multirow[t]{3}{*}{ Absent } & Nuchal rigidity & \\
\hline & & Kernig's sign & 0.200 \\
\hline & & Brudzinski's sign & 0.170 \\
\hline & \multirow[t]{3}{*}{ Present } & Nuchal rigidity & 0.640 \\
\hline & & Kernig's sign & 0.609 \\
\hline & & Brudzinski's sign & 0.527 \\
\hline
\end{tabular}

A summary of pretest and post-test probability of meningitis (bacterial and viral) according to clinical examination findings. Pretest probability derived from ref ${ }^{3}$. Post-test probabilities calculated using likelihood ratios from ref ${ }^{2}$.

\section{Case 3: Are clinical signs of meningism useful in children under the age of 1 year?}

Children below the age of 2 months were not included in any study that quantified the performance of clinical signs of meningitis (table 1 ). Consensus opinion is that these examination findings are unreliable in infants. ${ }^{8}$

Furthermore, the risks of meningitis are much higher in young infants than in older children. For example, a prospective study of infants under the age of 90 days who presented with fever without source found the prevalence of bacterial meningitis to be $0.458 \%$. $^{9}$ Therefore, it is necessary to maintain a higher index of suspicion for meningitis when infants present with fever.

For this reason, the National Institute for Health and Care Excellence guidelines recommend LP in febrile infants under the age of 1 month, and in febrile infants aged 1-3 monthswho appear unwell. ${ }^{10}$

\section{Clinical bottom line}

- Bacterial meningitis is uncommon in children over the age of 1 year.

- Meningitis can be difficult to detect clinically.

- The absence of Kernig's sign, Brudzinski's sign and nuchal rigidity is reassuring in low-risk settings but cannot fully exclude meningitis.

- The presence of Kernig's sign, Brudzinski's sign and nuchal rigidity confers enough risk to justify further investigation.
Contributors AT conceived the work and contributed to the interpretation of data, drafting the manuscript and revising for intellectual content. TW contributed to the interpretation of data, drafting the manuscript and revising for intellectual content, and designed the figures.

Funding The authors have not declared a specific grant for this research from any funding agency in the public, commercial or not-for-profit sectors.

Competing interests None declared.

Patient consent Parental/guardian consent obtained.

Provenance and peer review Commissioned; externally peer reviewed.

ORCID iD

Alexander Tracy http://orcid.org/0000-0003-4109-3568

\section{REFERENCES}

1 Ward MA, Greenwood TM, Kumar DR, et al. Josef Brudzinski and Vladimir Mikhailovich Kernig: signs for diagnosing meningitis. Clin Med Res 2010;8:13-17.

2 Curtis S, Stobart K, Vandermeer B, et al. Clinical features suggestive of meningitis in children: a systematic review of prospective data. Pediatrics 2010;126:952-60.

3 Verbakel JY, Lemiengre MB, De Burghgraeve T, et al. Point-ofcare $\mathrm{C}$ reactive protein to identify serious infection in acutely ill children presenting to hospital: prospective cohort study. Arch Dis Child 2018;103:420-6.

4 Lehmann D, Yeka W, Rongap T, et al. Aetiology and clinical signs of bacterial meningitis in children admitted to Goroka Base Hospital, Papua New Guinea, 1989-1992. Ann Trop Paediatr 1999;19:21-32.

5 Amarilyo G, Alper A, Ben-Tov A, et al. Diagnostic accuracy of clinical symptoms and signs in children with meningitis. Pediatr Emerg Care 2011;27:196-9.

6 Berkley JA, Versteeg AC, Mwangi I, et al. Indicators of acute bacterial meningitis in children at a rural Kenyan district hospital. Pediatrics 2004;114:e713-e719.

7 Bilavsky E, Leibovitz E, Elkon-Tamir E, et al. The diagnostic accuracy of the 'classic meningeal signs' in children with suspected bacterial meningitis. Eur J Emerg Med 2013;20:361-3.

8 Nice. 'National Institute for Health and care excellence'. meningitis and meningococcal septicaemia in under 16s: recognition, diagnosis and management. 2015:1-5 https:// www.nice.org.uk/guidance/cg102? unlid = 501397575201 621231125 (accessed 9 Aug 2018).

9 Gomez B, Mintegi S, Bressan S, et al. Validation of the "stepby-step" approach in the management of young febrile infants. Pediatrics 2016;138:e20154381.

10 National Institute for Health and Care. Fever in under $5 \mathrm{~s}$ : assessment and initial management. https://www.nice.org. uk/guidance/cg160 (accessed 9 Aug 2018).

11 Offringa M, Beishuizen A, Derksen-Lubsen G, et al. Seizures and fever: can we rule out meningitis on clinical grounds alone? Clin Pediatr 1992;31:514-22. 